\title{
0 mercado de bens e serviços com apelos ambientais
}

\author{
The market for goods and services with environmental appeals
}

\author{
Eliana Boaventura Bernardes Moura Alves ${ }^{1}$ \\ Kelly de Oliveira Barros² \\ Nathália Granato Loures 3 \\ Laércio Antônio Gonçalves Jacovine ${ }^{4}$ \\ Ricardo Ribeiro Alves 5
}

\section{Resumo}

A crescente conscientização ambiental da sociedade tem alavancado o consumo de produtos e serviços com apelo ambiental, formando o denominado "mercado verde", que tem impulsionado a economia e estimulado o desenvolvimento sustentável. Este trabalho teve como objetivo analisar o mercado de bens e serviços com apelos ambientais e inferir sobre suas motivações e tendências. O método utilizado foi a pesquisa bibliográfica, a fim de construir um estudo descritivo que reunisse e compilasse informações deste mercado. Constatou-se que o marketing aliado à responsabilidade ambiental vem alcançando cada vez mais espaço nos meios de comunicação das empresas e funciona como ferramenta estratégica, favorecendo a imagem corporativa e a competitividade, além de conquistar e fidelizar consumidores. 0 "mercado verde" revela tendências de crescimento, tanto no quesito número de consumidores, como também de competidores. Tal fato pode requerer um marketing mais agressivo e mais informativo por parte das empresas, no intuito de manter e conquistar novos clientes.

\section{Palavras-chave}

Apelo ambiental

Bens e serviços ambientais

Marketing verde.

Práticas ecológicas.

\section{Abstract}

The increasing environmental awareness of the society has promoted the consumption of products and services with environmental appeal, building the so called 'green market', which has stimulated the economy and motivating the sustainable development. This study aimed to analyze the market for goods and services with environmental appeals and to infer about their motivations and trends. The method used was the literature search to build a descriptive study in order to gather and compile information about this market. It was verified that marketing, together with environmental responsibility, has been acquiring more and more space in the business media and works as a strategic tool, promoting the corporate image and competitiveness, helping to get new customers and develop their loyalty. The 'green market' shows growth trends both the number of consumers, and competing numbers. This may require a more aggressive and informative marketing from the companies, in order to keep and get new clients.

\section{Key words \\ Environmental appeal \\ Environmental goods and services \\ Green Marketing \\ Ecological practices.}




\section{1 | Introdução}

O processo da globalização contribui para uma transformação mais acelerada nos diversos setores da sociedade e da economia. Novos conceitos, descobertas, paradigmas, valores e mercados, assim como também tecnologias, surgem e são inovados diariamente. É neste cenário de mudanças aceleradas e de desenvolvimento industrial que se observam intensas discussões sobre as consequências deste comportamento global e suas repercussões no meio ambiente (LIRA; ALMEIDA, 2008)

As reflexões sobre a qualidade de vida da população e a preservação ambiental fizeram com que a responsabilidade social, o desenvolvimento sustentável e o consumo consciente se incorporassem à rotina de empresas, sociedade e governo, refletindo uma necessidade de mudança do comportamento em prol do benefício comum (GIORGETTI, 2007; DALMORO et al., 2009).

O consumo e o desperdício dos recursos ambientais estão sendo denunciados por veículos de informação, principalmente a partir do final do século XX. Desde então, o empenho de ambientalistas engajados nesta causa, assim como a própria consciência ambiental da população, mostram crescimento constantes (DAMASCENO et al., 2008).

O mercado de bens e serviços com apelo ecológico agrega o foco da responsabilidade ambiental a uma estratégia de marketing (conhecido como marketing verde), destacando, desta forma, o compromisso com o meio ambiente por parte da empresa em sua relação com os consumidores (SCARPINELLI; RAGASSI, 2003).

A preocupação com as questões ambientais tornar-se um quesito diferencial e ao mesmo tempo relevante nas relações de consumo. $\mathrm{O}$ mercado, sempre atento às tendências, percebe que bens e serviços com apelos ambientais são valorizados, resultando em uma demanda crescente por produtos que adotem, na sua cadeia produtiva, posturas ecologicamente responsáveis. Diante disto, empresas passaram a incorporar estratégias de cunho ambiental em seus propósitos, como por exemplo, os certificados ecológicos e selos verdes de qualidade ambiental (LIRA; ALMEIDA, 2008). A associa- ção de uma imagem ambientalmente responsável a uma determinada empresa é apontada como um importante mecanismo para seu sucesso e crescimento, assim como para sua permanência e até para expansão de mercado (DAMASCENO et al., 2008).

É neste contexto que empresas que adotam o marketing verde estão utilizando de mensagens que falem a respeito da importância do consumo de seu produto em específico. Desta forma, novos consumidores são conquistados e fidelizados, tornando este tipo de marketing uma estratégia forte e promissora. Os benefícios são percebidos em todos os agentes envolvidos nesta análise: a empresa, que se empenha em lançar sempre novos produtos neste mercado; o meio ambiente, que se beneficia com o aumento de produtos nesta categoria ecológica, com a consequente redução de impactos ambientais, mesmo que de maneira indireta; e o próprio consumidor, que pode ter acesso a produtos mais saudáveis e que favoreçam o seu bem-estar (MOTTA, 2007; GIORGETTI, 2007).

Diante do exposto, objetivou-se com o trabalho analisar o mercado de bens e serviços com apelos ambientais e inferir sobre as motivações para estes apelos, assim como apontar suas tendências.

\section{2 | Material e Métodos}

Este estudo caracteriza-se como uma pesquisa de natureza descritiva. Vergara (2000) citou que a pesquisa descritiva "não tem o compromisso de explicar os fenômenos que descreve, embora sirva de base para tal explicação" e argumentou que a mesma expõe as características de determinada população ou fenômeno, estabelece correlações entre variáveis e define sua natureza.

O método utilizado foi a pesquisa bibliográfica que, de acordo com Macedo (1996), representa a busca da informação bibliográfica de forma planejada e se relaciona com a identificação, localização, obtenção, fichamento e organização de documentos, com a finalidade de documentar um trabalho de pesquisa. No caso do presente trabalho, foram pesquisadas teses, dissertações, artigos em periódicos e notícias em geral, disponíveis em meio impresso e digi- 
tal, que contemplassem o tema abordado, além de dados secundários, com o intuito de analisar e avaliar como o mercado de bens e serviços ambientais está evoluindo e as suas tendências.

\section{3 | Resultados e discussão}

\section{Empresas e produtos que fazem uso dos apelos ambientais}

Donaire (1999) destacou que a área de marketing, ao incorporar a variável ecológica na condução de suas decisões, deve preocupar-se principalmente com "o desenvolvimento de produtos que possibilitem melhorias em atributos ambientais, não só no que diz respeito à sua produção e uso, mas também em relação a embalagens mais adequadas ao ambiente, distribuição sem riscos e descarte sem resíduos".

O fornecimento de bens e serviços para diminuir a poluição e para possibilitar uma meIhor gestão dos recursos ambientais tem se tornado o carro chefe de empresas privadas especializadas nas últimas décadas. Os bens e serviços ambientais constituiriam um "setor" cujo porte seria equivalente aos dos setores aeroespacial e farmacêutico em conjunto, com um mercado global estimado de quase US\$ 800 bilhões em 2010 (ABDI, 2012).

Nestes últimos anos, vem ocorrendo um aumento da oferta de produtos considerados ecologicamente corretos ou "produtos verdes" e, segundo estudo de Mintuwimsatt e Bradford (1995), citado por Motta (2007), isto se dá principalmente em função de uma resposta mercadológica das empresas às pressões que grupos de consumidores mais preocupados com as questões ambientais começaram a exercer.

No trabalho desenvolvido por Motta (2007) são apresentados os atributos que os produtos considerados ecologicamente corretos podem possuir, sendo eles: fabricado com matérias-primas renováveis, inclusive embalagem; fabricado com a quantidade mínima de matérias-primas e/ou materiais; fabricado com matérias-primas que conservam recursos naturais no processo de extração; fabricado com a máxima eficiência energética e de utilização de água; fabricado com o despejo mínimo de efluentes e resíduos; envasado em embalagens mais leves; envasado em embalagens mais volumosas; concentrado; mais durável; presta- se a múltiplos propósitos; é mais facilmente consertado; tem maior eficiência energética quando utilizado; conserva recursos naturais quando utilizado; é reciclável; é reutilizável; pode ser refabricado; é biodegradável e é substituído por refil.

Motta (2007) também apresentou alguns exemplos de empresas sediadas no Brasil que já lançaram produtos ambientalmente corretos, como a resina atóxica "Ecopiso" e a cola de alta adesão "Eco-adesivo", da Sealcolor; tinta látex acrílica "Eco Acqua", da Midas Elastômeros, um látex fabricado sem solventes nem compostos orgânicos voláteis, da Renner; a linha "Metalatex Eco", da Metalatex, fabricado sem solventes, com base em água; linha de torneiras e vasos sanitários que economizam água, da Deca; açúcar orgânico e ecológico "Native", da Usina São Francisco; arroz orgânico "Nardelli Bio", da Alimentos Nardelli; geladeiras "verdes", que consomem menos energia elétrica, lançadas por Multibras e Electrolux, e as que utilizam o gás natural R60o, não prejudicial à camada de ozônio, da Bosch; as madeiras certificadas com selo de manejo ambiental das empresas Juruá Madeiras e Gethal; o starter/alternador da Dana, que permite o desligamento do motor quando o veículo se encontra parado, o que diminui a emissão de polventes; a linha de pneus "Xapuri", da Pirelli; antenas e alarmes automotivos sem metais pesados, da Olimpus; "Ecol Denin", jeans ecológico desenvolvido pela Santista; creme dental "Sorriso Herbal", da Kolynos; lápis com madeira reflorestada, da Faber-Castell; "Post-it" ecológico da $3 \mathrm{M}$, juntamente com a Suzano; as empresas de comunicação TV Globo, TV Cultura e Rádio Eldorado AM, que apresentam, respectivamente, os programas "Globo Ecologia", "Repórter Eco" e "Terra, Fogo, Mar e Ar"; a Tramontina, empresa que atua no ramo de utilidades domésticas, inovou em seu mercado com móveis para jardim, cabos para ferramentas e utensílios para o lar confeccionados com madeira certificada; filtro de café "Eco", da Melitta; xales da Baobá Tecidos Artesanais, feitos com PET a partir de garrafas de refrigerantes recicladas; papel para impressão reciclado "Reciclato", da Suzano; leite orgânico "Naturallis", da Cemil.

Existem também outras empresas não citadas neste estudo de Motta (2007), nos mais diversos setores da economia, que estão 
investindo tempo e dinheiro a fim de promoverem um apelo ambiental a partir dos seus produtos, como por exemplo, a Coca-Cola, que vai ajudar a reciclar garrafas PET para fazer parte dos assentos dos estádios da Copa do Mundo (COCA-COLA, 2013); a Bombril, principalmente com a Linha Ecobril, que possui um processo de fabricação sustentável, utilizando matérias-primas renováveis adicionadas a ativos biodegradáveis, evitando impactos na natureza. Além de outros produtos da marca que utilizam embalagens totalmente recicláveis, que não contém CFC, que utilizam plásticos reciclados, entre outros apelos ambientais (BOMBRIL, 2013); a Ypê, que utiliza embalagens que consomem menos matéria-prima e contribuem para uma menor emissão de $\mathrm{CO}_{2}$ em toda a cadeia de consumo, mantém um Sistema de Gestão Ambiental norteado pelos conceitos do Desenvolvimento Sustentável em todas as suas unidades e, em parceria com a SOS Mata Atlântica, ampliou o Projeto Florestas Ypê com o plantio de mais de cinquenta mil mudas de espécies nativas da Mata Atlântica, entre outros aspectos relacionados ao compromisso ambiental (YPE, 2013); e a Comfort Concentrado, que por sua fórmula ser concentrada ajuda na economia de água em sua produção, além de economizar plástico na fabricação das embalagens e diminuir a emissão de $\mathrm{CO}_{2}$ na sua distribuição (COMFORT, 2013).

Dessa forma, verifica-se que o Marketing Ambiental é estruturado e priorizado pelas empresas e, por meio da consulta em seus endereços eletrônicos, pode-se observar o destaque e a importância que são dados às questões ambientais, com foco na importância do consumo consciente.

No setor de cosméticos, as empresas que mais se destacam no Brasil são a Natura Cosméticos S/A e O Boticário. A Natura Cosméticos S/A apresenta gestão ambiental em seus processos e possui a certificação ISO 14.001. Além disso, possui uma política de meio ambiente, através da qual incentiva o uso de refis; disponibiliza nos produtos uma tabela com informações ambientais sobre o produto e a embalagem; possui a Linha Ekos, que valoriza a biodiversidade natural, entre outros aspectos que são levados em consideração pela empresa (NATURA, 2013). Já O Boticário integra o
Programa de Ecoeficiência, que tem o objetivo de reduzir os impactos ambientais do processo produtivo, além de possuir certificação OHSAS 18.001 e ISO 14.001. Adicionalmente, a empresa possui a Fundação Grupo Boticário de Proteção à Natureza, que atua junto à sociedade em um parque interativo em Curitiba (FUNDAÇÃO BOTICÁRIO, 2013; GRUPO BOTICÁRIO, 2013).

Os produtos orgânicos também são um exemplo do marketing com forte apelo ambiental. No estudo desenvolvido por Lira e Almeida (2008), verificou-se que quanto maior o nível de escolaridade, maior é a disponibilidade para pagar por este tipo de alimento. No entanto, percebeu-se que o consumo de produtos orgânicos é influenciado não apenas pelo quesito "nível de consciência da população", mas que o fator relacionado à renda exerce maior influência neste tipo de consumo. Da mesma forma acontece na Índia, onde a população urbana e com determinado nível de escolaridade, tem manifestado a consciência ambiental e reconhecido a importância dos produtos verdes (MAHESHWARI; MALHOTRA, 2011).

O marketing ambiental pode ser assimilado pelas empresas como uma ferramenta estratégica, e as instituições financeiras brasileiras também vêm apresentando uma evolução na direção da inclusão de práticas sustentáveis em seu modelo de negócios, gestão e produtos. Os bancos BNDES, do Brasil, Itaú Unibanco, Bradesco, Santander e outros, apoiam e desenvolvem produtos e serviços com apelo ambiental.

Em Viçosa (MG), mais precisamente no "Supermercado Escola", localizado na Universidade Federal de Viçosa (UFV), também é possível verificar um exemplo de empresa com apelo ambiental. O supermercado, em parceria com o Departamento de Engenharia Florestal da UFV, participa do projeto Super Ecológico, cujo principal objetivo é promover a sensibilização ambiental da comunidade universitária e de empresas do ramo alimentício sobre a utilização de sacolas plásticas e implementar formas alternativas para racionalização do seu uso. Além disto, os produtos com apelos ambientais existentes no supermercado são etiquetados com selos nas cores verde, azul e marrom, de acordo com suas características e informações, a fim de despertar o interesse do consumidor. O Selo Verde é utilizado com o intuito de demonstrar, à primeira vista, que 
aquele produto é certificado e possui um selo que autentica a cadeia de custódia e demais processos de produção daquele artigo. O Selo Azul refere-se àqueles produtos que possuem algum apelo ambiental informado ou declarado pelo fabricante, mas que não foi avaliado se a mensagem está correta. O Selo Marrom identifica nas prateleiras aqueles produtos que são, por eles próprios, menos danosos, seja por sua composição química, seja por possuírem refil, seja por possuírem um processo de produção menos impactante.

Por fim, existem empresas que buscam a certificação do sistema de gestão ambiental para legitimar suas ações e aplicam a gestão ambiental em suas atividades, há também outras empresas que vendem produtos de origem florestal, com certificação florestal (ALVES, 2010). Um exemplo é o papel obtido da celulose extraída de madeiras advindas de florestas certificadas e outras fontes controladas. Ações como esta permitem que a empresa ou o produto despertem o interesse de certos consumidores.

Independentemente de questões mercadológicas ou de real preocupação com o meio ambiente, é fato que o número de consumidores que preferem os produtos verdes vem crescendo, e esta ascensão pode trazer benefícios diretos ao capital natural.

\section{Motivações para os apelos ambientais e tendências para este mercado}

Mesmo com a divulgação da importância do meio ambiente para o empreendimento, os benefícios gerados pela adoção de medidas ecologicamente responsáveis no seu processo produtivo ou oferta de serviços é o que de fato move as empresas na direção da preservação/conservação ambiental (DAMASCENO et al., 2008).

Damasceno et al. (2008) identificaram em seu estudo que a principal preocupação do empreendimento que realiza um anúncio ecológico é com sua imagem corporativa. Nesta análise foi revelado que as características ecológicas do produto em divulgação acabam em segundo plano. A carência de informação mais detalhada sobre as atitudes ecologicamente responsáveis que, de fato, são tomadas por uma empresa, acabam por diversas vezes colocando em questão a credibilidade daquelas que têm esta postura, isto quando alguns consumi- dores analisam-nas de maneira mais criteriosa. Em relação a esta questão, Bukhari (2011) destacou a possibilidade das empresas terem suas marcas e vendas seriamente denegridas caso a alegação verde seja falsa ou divergente do que é mostrado. Em uma pesquisa feita com consumidores de São Paulo, Motta e Rossi (2003) perceberam que as decisões de consumidores no momento da compra não estão atreladas ao fator ecológico do produto, justificando este fato em razão da pouca informação disponível sobre quais produtos têm atitudes responsáveis para com o meio ambiente.

No entanto, se um empreendimento desenvolve o marketing verde de forma genuína e transparente, pode-se considerar esta uma excelente estratégia para conquistar novos clientes, aumentar os lucros e ter uma vantagem competitiva perante aquelas empresas que não demonstram preocupação com o meio ambiente. Desta forma, pode-se considerar uma tendência deste mercado que as empresas sejam cada vez mais transparentes e detalhadas no que se refere às suas atitudes ambientalmente responsáveis.

Para Bukhari (2011), o interesse de consumidores de todo o mundo em proteger o meio ambiente é crescente, e a evidência disto é a mudança do comportamento de pelo menos uma parcela da população, com o surgimento e ascensão do marketing verde. Paço et al. (2009), em estudo sobre o consumo verde em Portugal, demonstraram que consumidores deste país têm a consciência de um consumo ambiental responsável, que estariam dispostos a adquirir produtos verdes, mas que esta preocupação não é necessariamente traduzida em atitudes com responsabilidade ecológica.

Seja movido por questões financeiras ou não, o fato da população apresentar esta consciência ambiental pode ser considerado promissor e um verdadeiro estímulo para que as empresas adotem medidas ambientalmente responsáveis e participem deste "mercado verde", que tem sido cada vez mais disputado, ou ainda aquelas empresas que já adotam esta política, que se sintam estimuladas a desenvolver novas estratégias de vendas destes produtos e conquistem cada vez mais consumidores.

Deve-se reconhecer que o aumento da consciência ambiental da população é um estímulo para que os responsáveis por decisões da área 
comercial adotem novas práticas relacionadas ao Marketing Verde em sua gestão, já que aqueles produtos que não adotarem práticas ambientalmente responsáveis perderão credibilidade para com os seus consumidores, enquanto que os produtos verdes terão um mercado amplo e cada vez mais promissor (PAÇO et al., 2009).

Motta e Rossi (2003) consideraram o lançamento de produtos verdes no Brasil ainda incipiente, entendendo a dificuldade que as empresas brasileiras têm de utilizar esta ideia ambiental como uma estratégia de competitividade. No entanto, em uma pesquisa mais recente, Damasceno et al. (2008) perceberam que a responsabilidade ambiental encontra-se presente entre as maiores empresas do país, e que o crescimento deste tipo de marketing é uma concepção real para as companhias brasileiras. De fato, Häsner e Romero (2010) relataram a respeito do mercado ambiental no país, afirmando que seu crescimento acentuado pôde ser percebido a partir do ano 2000, com um crescimento bastante significativo, de US\$ 3,77 a 17,21 bilhões. Estes autores ainda consideraram o mercado ambiental como bastante promissor para o mundo, enfatizando o Brasil neste cenário.

As mensagens encontradas nas embalagens induzem o consumidor à ideia de que a aquisição de determinado produto, por conta de suas características e da política de cunho ambiental da indústria que o concebe, o faz colaborar com uma atitude em benefício de si mesmo e mesmo da humanidade (GIORGETTI, 2007). É neste sentido que se pode prever uma forte tendência das empresas que utilizam o marketing ambiental em fazer uso de mensagens cada vez mais manipuladoras para conquistar consumidores indecisos e fidelizar aqueles que já compram seus produtos.

\section{4 | Conclusão}

A principal motivação das empresas em adotar o marketing ambiental está relacionada à sua imagem corporativa e, consequentemente, ao aumento da demanda dos consumidores que prezam por esses produtos e serviços, e os benefícios financeiros que tais atitudes renderão.
A transição para uma economia verde é extremamente desejável do ponto de vista ambiental. Observa-se uma tendência de crescimento do "mercado verde", com mais consumidores e competidores, e isso pode requerer um marketing mais agressivo e mais informativo para conquistar e fidelizar os clientes.

\section{Referências bibliográficas}

AGÊNCIA BRASILEIRA DE DESENVOLVIMENTO INDUSTRIAL (ABDI). Relatório de Acompanhamento Setorial de Competitividade do Setor de Bens e Serviços Ambientais. 2012. Disponivel em: <http://www.abdi.com.br/Estudo/000\%20-\%2obens_servicos_ambientais $\% 20$ definitivo.pdf.> Acesso em: 20 jan. 2012.

ALVES, R. R. Marketing, estratégia competitiva e viabilidade econômica para produtos com certificação de cadeia de custódia na indústria moveleira. 2010. $367 \mathrm{f}$. Tese (Doutorado em Ciência Florestal). Universidade Federal de Viçosa, Viçosa - MG, 2010.

BOMBRIL, 2013. Linha Bombril Sustentável. Disponivel em: <http://www.ecobril.com.br/ > Acesso em: 26 jan. 2013.

BUKHARI, S. S. Green Marketing and its impact on consumer behavior. European Journal of Business and Management. , v. 3, n. 4, 2011. Disponivel em: <http://www.iiste.org/Journals/ index.php/EJBM/article/view/322/211>. Acesso em: 25 jan. 2013.

COCA-COLA, 2013. Reciclagem das garrafas PET de Coca-Cola. Disponível em: < http:// assentospet.cocacola.com.br/assentospet/ > Acesso em: 21 jan. 2013.

COMFORT, 2013. Comfort concentrado. Disponivel em: <http://www.comfort.com.br/ meio-ambiente> Acesso em: 21 jan. 2013.

DALMORO, M.; VENTURINI, J. C.; PEREIRA, B. A. D. Marketing Verde: responsabilidade social e ambiental integradas na envolvente de marketing. Revista Brasileira de Gestão de Negócios. v. 11, n. 30, p. 38-52, 2009. Disponível em: <http://200.169.97.104/seer/index.php/RBGN/ar- 
ticle/viewFile/232/445> Acesso em: 25 jan. 2012.

DAMASCENO, A. L.; PRADO FILHO, J. F.; CAMARGOS, S. P. Práticas e produtos ambientalmente sustentáveis: análise do conteúdo das informações veiculadas em revista de circulação no Brasil. Gestão da Produção, Operação e Sistemas. n. 3, p. 11-23, 2008. Disponivel em: <http://revista.feb.unesp.br/index.php/index/ search/results $>$. Acesso em: 25 jan. 2013. DONAIRE, D. Gestão ambiental na empresa. 2 ed., São Paulo: Editora Atlas, 1999. p. 169.

FUNDAÇÃO GRUPO BOTICÁRIO DE PROTEÇÃO À NATUREZA, 2013. Disponível em: $<w w w$.fundacaogrupoboticario.org.br>. Acesso em: 22 jan. 2013.

GIORGETTI, C. O Marketing Ambiental como produto da modernidade reflexiva e o exemplo do café. Revista FACOM. n. 18, p. 39-41, 2007,. Disponível em: < http://www.faap.br/revista_faap/revista_facom/facom_18/indice.htm> Acesso em: 25 jan. 2013.

GRUPO BOTICÁRIO, 2013. Programa de Ecoeficiência. Disponível em: www.grupoboticario. com.br. Acesso em: 21 jan. 2013.

HÄSNER, C. A. D.; ROMERO, T. C. Mercado de Bens e Serviços Ambientais: Desafios e Oportunidades. Pontes (Impresso), v. 6, p. 14-16, 2010. Disponível em:<http://www.prospective.com.br/artigos/6/Pontes_bimestral_v6n3_ Cecilia_e_Tereza_2010.pdf> Acesso em: 22 jan. 2013.

LIRA, R. A.; ALMEIDA, L. C. O consumidor verde em Campos dos Goytacazes/RJ. Revista Perspectivas online. v. 5, n, 1, p. 51-64, 2008. Disponivel em: <http://www.perspectivasonline.com.br/revista/2008vol2n5/volume\%20 2(5)\%2oartigo6.pdf > Acesso em: 24 jan. 2013.

MAHESHWARI, A.; MALHOTRA, G. Green Marketing: A Study on Indian Youth.

International Journal of Management and Strategy. v. 2, n. 2, 2011. Disponível em: <http://www.facultyjournal.com/webmaster/ upload/_Gunjan\%2oMalhotra\%2olM T\%20 Gzd.pdf> Acesso em: 25 jan. 2013.
MACEDO, N. D. Iniciação à pesquisa bibliográfica. São Paulo: Loyola, 1996. 69 p.

MOTTA, S. L. S. Motivações para o lançamento de um produto ecologicamente correto: um estudo de caso. Revista de Gestão, USP, São Paulo, v. 14, n. 1, p. 31-40, jan.mar. 2007. Disponível em: <http://www.revistas.usp.br/rege/article/ view/3658 8/39309>. Acesso em: 25 jan. 2013.

MOTTA, S. L. S.; ROSSI, G. B. A influência do fator ecológico na decisão de compra de bens de conveniência: um estudo exploratório na cidade de São Paulo. Revista de Administração, São Paulo, v. 38, n. 1, p. 46-57 2003. Disponível em: <www.rausp.usp.br/busca/artigo. asp?num_artigo=1079>. Acesso em: 22 jan. 2013.

NATURA, 2013. Política Ambiental da Natura. Disponível em: <www.natura.net $>$ Acesso em: 22 jan. 2013.

PAÇO, A. M. F.; RAAPOSO, M. L. B.; LEAL FILHO, W. Identifying the green consumer: A segmentation study. Journal of Targeting, Measurement and Analysis for Marketing. $n$. 1, v. 17, p. 17-25, 2009. Disponivel em: <http:// www.palgrave-journals.com/jt/journal/v17/n1/ pdf/jt200828a.pdf>. Acesso em: 25 jan. 2013.

SCARPINELLI, M.; RAGASSI, G. F. Marketing verde: ferramenta de gestão ambiental nas empresas. Revista Científica Eletrônica de Ciência Contábeis. n, 2, 2003. Disponível em: <http://www.revista.inf.br/contabeiso2/pages/ artigos/cc-edico2-anoi-art 04.pdf> Acesso em: 22 jan 2013.

VERGARA, S. C. Projetos e relatórios de pesquisa em administração. 3. ed. São Paulo: Atlas, 2000. p. 94.

YPE, 2013. Projeto Florestas Ypê. Disponível em:<www.ype.ind.br>Acesso em: 22 jan. 2013. 


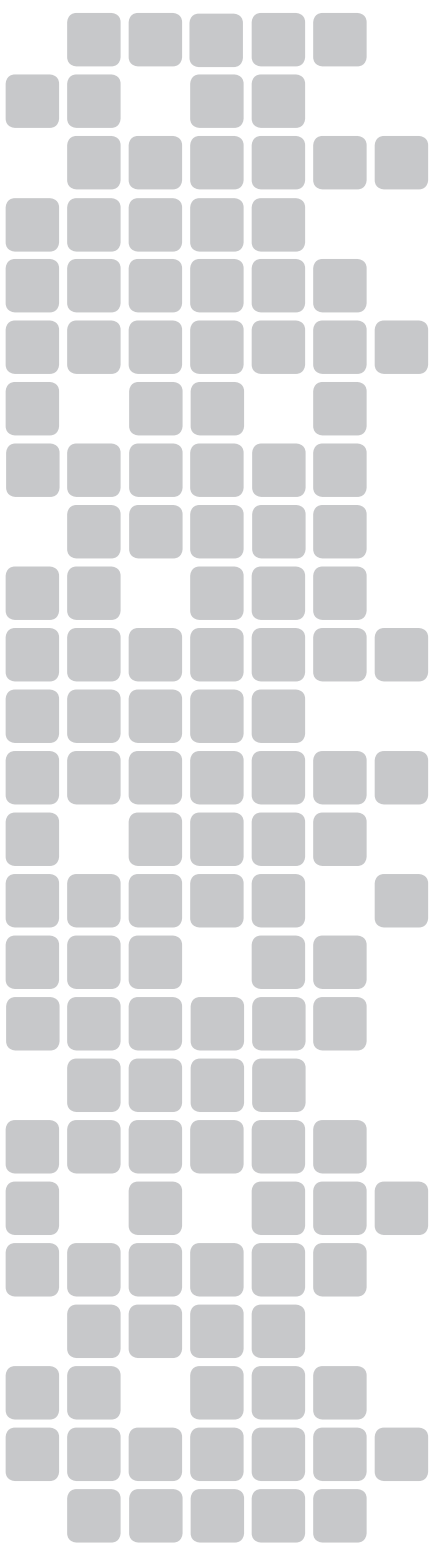

1 Universidade Federal de Viçosa, pesquisadora de mestrado. Viçosa, Minas Gerais, Brasil. elianabbm@gmail.com. (031) 3899-2469. Av. P. H. Rolfs, s/n - Departamento de Engenharia Florestal, Campus Universitário, Viçosa, Minas Gerais, CEP 36.570-000.

2 Universidade Federal de Viçosa, pesquisadora de doutorado. Viçosa, Minas Gerais, Brasil. kellyobarros@yahoo.com.br. (031) 3899-2477. Av. P. H. Rolfs, s/n - Departamento de Engenharia Florestal, Campus Universitário, Viçosa, Minas Gerais, CEP 36.570-000.

3 Universidade Federal de Viçosa, pesquisadora de mestrado. Viçosa, Minas Gerais, Brasil. nathaliagranato@yahoo.com.br. (031) 3899-2469. Av. P. H. Rolfs, s/n - Departamento de Engenharia Florestal, Campus Universitário, Viçosa, Minas Gerais, CEP 36.570-000.

4 Universidade Federal de Viçosa, professor associado. Viçosa, Minas Gerais, Brasil. jacovine@ufv.br. (031) 3899-1191. Av. P. H. Rolfs, s/n - Departamento de Engenharia Florestal - $3^{\circ}$ andar - gabinete 209 B, Campus Universitário, Viçosa, Minas Gerais, CEP $36.570-000$.

5 Universidade Federal do Pampa, professor adjunto II. São Gabriel, Rio Grande do Sul, Brasil. ricardoalves@unipampa. edu.br. (055) 8108-4489. Av. Antonio Trilha, 1847 - Il piso (Unipampa), Bairro Centro, São Gabriel, Rio Grande do Sul, CEP 97.300-000. 